\title{
Model Optimasi Penentuan Jumlah Dosen dan Ruangan Pada Proses Belajar Mengajar dengan Model Integer Linear Programming
}

\author{
Fajar Hidayat ${ }^{1}$, Dedy Hartama ${ }^{2}$, Agus Perdana Windarto ${ }^{3}$, Anjar Wanto ${ }^{4}$, Poningsih ${ }^{5}$ \\ ${ }^{12345}$ STIKOM Tunas Bangsa Pematangsiantar \\ Jl. Jend. Sudirman Blok A No. 1, 2, \& 3 Pematangsiantar \\ Telp. (0622)-22431 Fax. (0622)-7436800 \\ fajarhidayat011@gmail.com
}

\begin{abstract}
Class matrix is a scheduling of teaching a subject in accordance with the current curriculum. The problems that are often faced at the beginning of each semester are the intersection between one schedule and another. During this time the main cause was the increase in the number of students who always soared up each year which was inversely proportional to the limited number of classrooms or laboratory space and did not experience capacity development. This study aims to find a formulation to overcome the problems mentioned above. The method used in this study is Integer Linear Programming. With this algorithm can optimize the problems that exist in the preparation of the class matrix.
\end{abstract}

Keywords : integer linear programming, class matrix, optimization

Abstrak- Matriks kelas merupakan suatu penjadwalan pengajaran suatu matakuliah sesuai dengan kurikulum yang berlaku pada saat itu. Permasalahan yang kerap dihadapi setiap awal semester yaitu saling bersinggungannya antara jadwal yang satu dengan jadwal lainnya. Selama ini yang menjadi penyebab utamanya yaitu peningkatan jumlah mahasiswa yang selalu melonjak naik di setiap tahunnya yang berbanding terbalik dengan jumlah ruangan kelas ataupun ruang laboratorium yang terbatas dan tidak mengalami perkembangan kapasitas. Penelitian ini bertujuan untuk menemukan formulasi untuk menagatasi permasalahan tersebut di atas. Metode yang digunakan dalam penelitian ini yaitu Integer Linear Programming. Dengan algoritma ini dapat mengoptimalkan permasalahan yang ada dalam penyusunan matiks kelas.

Kata Kunci : integer linear programming, matriks kelas, optimisasi

\section{PENDAHULUAN}

Ruangan merupakan salah satu infrastruktur terpenting dalam proses belajar mengajar pada sebuah lembaga pendidikan. Ketersediaan ruangan biasa dikenal dengan University Class Scheduling Problem (UCSP) / timetabling problem. UCSP ini merupakan sebuah kondisi yang menunjukkan kurang optimalnya penyusunan strategi antara sumber daya yang tersedia terhadap keterbatasan yang ada sehingga dibutuhkan sebuah sitem penjadwalan. Selain ruangan, dalam proses belajar mengajar juga didukung oleh Sumber Daya Manusia (SDM). Salah satu sumber daya yang berada dalam ruang lingkup perguruan tinggi yang harus dikelola dan dikembangkan secara berkesinambungan yakni sumber daya manusia manusia (Dosen), karena "Dosen" merupakan sumber pengetahuan, keterampilan, dan kemampuan yang terakumulasi dalam diri anggota organisasi atau perguruan tinggi [1]. STIKOM Tunas Bangsa Pematangsiantar merupakan salah satu Perguruan Tinggi Swasta di Sumatera Utara yang bertujuan untuk meningkatkan dan mengembangkan watak dan kepribadian generasi muda yang unggul di bidang 
ilmu komputer dalam tatanan global dalam rangka usaha menyongsong datangnya abad milenial, sehingga harus didukung oleh tenaga kerja edukatif dan fungsional yang berkompeten dibidangnya. STIKOM Tunas Bangsa Pematangsiantar memiliki sejumlah ruangan dalam mendukung kelancaran proses belajar mengajar, seperti ruangan kelas, dan ruang laboratorium. Namun seiring berkembangnya jumlah mahasiswa setiap tahunnya dan kebutuhan ruanganpun semakin meningkat. Peningkatan ini berimbas pada kompleksitas dalam pengalokasian ruangan, sehingga metode penjadwalan yang tepat sangat dibutuhkan.

Beberapa peneliti telah mencoba memodelkan UCSP dengan beberapa algoritma yaitu algoritma Tabu Search [2], Simmulated Annealing [3], Algoritma Genetika [4], dan Integer Linear Programming (ILP) [5]. Masing-masing algoritma dari peneliti tersebut memiliki kelebihan dan kelemahan tersendiri. Seperti pada Algoritma Genetika, Semakin banyak jumlah individu yang dibangkitkan maka akan semakin sedikit jumlah crash/bentrok yang terjadi maka solusi yang dihasilkan akan semakin lebih baik [6], dengan kata lain hasil dari algoritma tersebut tidak bersifat optimum global. Hasilnya akan sangat dipengaruhi oleh jumlah besarnya data yang diolah. Salah satu algoritma yang dapat menyederhanakan UCSP ini adalah Integer Linear Programming (ILP), sebab Integer Linear Programming mampu mengolah data dalam jumlah besar dan dengan constraint (kendala) yang lebih besar pula. ILP merupakan model program linier dengan persyaratan tambahan yaitu beberapa atau semua variabel keputusan harus merupakan bilangan bulat. Penggunaan variabel bilangan bulat memberikan tambahan fleksibilitas dalam pembuatan model [7].

\subsection{Optimasi}

Optimasi (Optimization) adalah aktivitas untuk mendapatkan hasil terbaik di bawah keadaan yang diberikan. Tujuan akhir dari semua aktivitas tersebut adalah me minimumkan usaha (effort) atau memaksimumkan manfaat (benefit) yang diinginkan [8]. Optimasi yaitu proses mencari solusi yang terbaik atau nilai optimal dari permasalahan optimasi. Permasalahan-permasalahan optimasi tersebut ada yang mencari nilai maksimal atau nilai minimal. Serta permasalahan optimasi banyak dijumpai dalam kehidupan sehari-hari, seperti bidang matematika, teknik, sosial, ekonomi, pertanian, farmasi, otomotif, dan lain-lain. Permasalahan [9].

\subsection{Integer Linear Programming}

ILP adalah suatu model LP dengan variabel yang digunakan berupa bilangan bulat (integer). Jika semua variabel harus berupa integer, maka masalah tersebut dinamakan pure integer programming. Jika hanya sebagian yang harus berupa integer, maka disebut mixed integer programming (MIP). ILP dengan semua variabelnya harus bernilai 0 atau 1 disebut 0-1 ILP (Garfinkel \& Nemhauser 1972) [10]. Komponen utama integer linear Programming antara lain [11] :

a. Variabel Keputusan

$\mathrm{x}_{1}, \mathrm{x}_{2}, \ldots, \mathrm{x}_{\mathrm{n}}$ pada persamaan disebut variabel keputusan. Jumlah atau nilai suatu komponen pada sistem di dunia industri yang dinyatakan dalam bentuk variabel dinamakan variabel keputusan.

b. Fungsi Objektif 
Fungsi objektif adalah suatu kriteria yang ingin dioptimalkan (minimum/maksimum), diekspresikan sebagai sebuah fungsi linear kemudian dinotasikan sebaga z. Bentuk maksimisasi fungsi objektif dapat diubah menjadi bentuk minimalisasi dengan cara mengalikan fungsi objektif dengan bilangan negatif satu sehingga fungsi objektif pemrograman linear secara umum dikenal dalam bentuk masalah minimisasi.

c. Fungsi Kendala

Fungsi kendala adalah kumpulan fungsi yang berupa batasan dari sistem yang harus dipenuhi pada proses penyelesaian, diekspresikan sebagai kumpulan fungsi linear. sebuah vektor $\mathrm{x}=\left(\mathrm{x}_{1}, \ldots, \mathrm{x}_{\mathrm{n}}\right)$ yang memenuhi semua fungsi kendala disebut solusi feasible. Masalah pemrograman linear digunakan untuk menemukan solusi feasible yang meminimisasi fungsi objektif.

\section{METODOLOGI PENELITIAN}

Metode penelitian kualitatif merupakan metode yang berlandaskan pada filsafat post positifisme, serta sebagai metode artistic karena proses penelitian lebih bersifat seni (kurang terpola), dan disebut metode interpretive karena data hasil penelitian lebih berkenaan dengan interpretasi terhadap data yang di temukan di lapangan. Metode penelitian kualitatif sering di sebut metode penelitian naturalistik karena penelitianya di lakukan pada kondisi yang alamiah (natural setting), di sebut juga metode etnographi, karena pada awalnya metode ini lebih banyak di gunakan untuk penelitian bidang antropologi budaya [12].

Pengumpulan data merupakan proses pengadaan data primer, untuk kebutuhan suatu penelitian. Adapun teknik pengumpulan data dalam penelitian ini yaitu : [13]

1. Penelitian Kepustakaan (Library Research) yaitu memanfaatkan perpustakaan sebagai sarana dalam mengumpulkan data, dengan mempelajari buku - buku sebagai bahan referensi. Hal ini dilakukan dengan membaca tulisan berupa buku dan jurnal yang berkaitan dengan kasus yang penulis angkat.

2. Penelitian Lapangan (Field Work Research) yaitu penelitian yang dilakukan secara langsung dilapangan dengan menggunakan beberapa teknik yaitu obeservasi dan wawancara.

\subsection{Analisis data}

Metode analisis data terdiri atas dua macam, yaitu metode statistik deskriptif dan metode statistik inferensial. Jika pada metode penelitian penulis menggunakan metode penelitian kuantitatif, maka metode analisa data yang penulis gunakan adalah metode statistik inferensial. Statistik inferensial adalah statistik yang berkaitan dengan analisis data (sampel), kemudian diambil kesimpulan yang digeneralisasikan kepada seluruh populasi [14]. Analisis statistik inferensial dapat dikatakan sebagai metode analisis dengan menggunakan data yang berbentuk angka dan di analisis dengan cara membandingkan melalui perhitungan dan mengaplikasikannya dengan cara menggunakan rumus yang sesuai. Analisis statistik inferensial digunakan untuk menguji parameter populasi data yang ada, dengan menggunakan data yang berasal dari responden [15].

Dari hasil pengumpulan data diatas, penulis memperoleh beberapa data yang dibutuhkan untuk menyelesaikan kasus ini diantaranya sebagai beikut : 
1. Ruangan

Adapun data ruangan yang digunakan untuk proses belajar mengajar di STIKOM Tunas Bangsa Pematangsiantar adalah sebagai berikut :

Table 1. Ruangan

\begin{tabular}{|c|l|c|}
\hline NO & \multicolumn{1}{|c|}{ RUANGAN } & KAPASITAS \\
\hline 1 & III-202 (Lab 05) & 48 \\
\hline 2 & III-203 & 50 \\
\hline 3 & III-204 & 50 \\
\hline 4 & III-301 & 50 \\
\hline 5 & III-302 & 50 \\
\hline 6 & III-303 (lab 06) & 48 \\
\hline 7 & III-304 & 50 \\
\hline 8 & III-305 & 50 \\
\hline 9 & III-306 & 48 \\
\hline 10 & III-307 & 48 \\
\hline 11 & III-308 & 48 \\
\hline 12 & III-401 (lab 07) & 48 \\
\hline
\end{tabular}

2. Kelas

Adapun data kelas atau himpunan mahasiswa yang mengikuti proses belajar mengajar di STIKOM Tunas Bangsa Pematangsiantar adalah sebagai berikut :

Tabel 2. Kelas

\begin{tabular}{|c|c|c|}
\hline No & Kelas & Jumlah Mahasiswa \\
\hline 1 & $15 S 01$ & 33 \\
\hline 2 & $15 S 02$ & 29 \\
\hline 3 & $15 S 03$ & 21 \\
\hline 4 & $15 S 04$ & 28 \\
\hline 5 & $15 S 05$ & 29 \\
\hline 6 & $16 \mathrm{~S} 01$ & 32 \\
\hline 7 & $16 S 02$ & 38 \\
\hline 8 & $16 \mathrm{~S} 03$ & 32 \\
\hline 9 & $16 \mathrm{~S} 04$ & 42 \\
\hline 10 & 17S01 & 46 \\
\hline 11 & 17S02 & 42 \\
\hline 12 & $17 \mathrm{~S} 03$ & 37 \\
\hline 13 & $17 \mathrm{~S} 04$ & 46 \\
\hline 14 & $18 \mathrm{~S} 01$ & 48 \\
\hline 15 & $18 \mathrm{~S} 02$ & 48 \\
\hline 16 & $18 \mathrm{~S} 03$ & 49 \\
\hline 17 & $18 \mathrm{~S} 04$ & 48 \\
\hline 18 & $18 S 05$ & 17 \\
\hline 19 & $15 \mathrm{~T} 01$ & 21 \\
\hline 20 & $15 \mathrm{~T} 02$ & 26 \\
\hline 21 & $15 \mathrm{~T} 03$ & 30 \\
\hline 22 & $16 \mathrm{~T} 01$ & 39 \\
\hline 23 & $16 \mathrm{~T} 02$ & 27 \\
\hline 24 & $16 \mathrm{~T} 03$ & 43 \\
\hline 25 & $17 \mathrm{~T} 01$ & 44 \\
\hline 26 & 17T02 & 41 \\
\hline 27 & 17T03 & 47 \\
\hline 28 & 18T01 & 48 \\
\hline
\end{tabular}




\begin{tabular}{|l|l|c|}
\hline No & Kelas & Jumlah Mahasiswa \\
\hline 29 & $18 \mathrm{~T} 02$ & 47 \\
\hline 30 & $18 \mathrm{~T} 03$ & 49 \\
\hline
\end{tabular}

3. Dosen

Adapun data dosen yang mengajar di STIKOM Tunas Bangsa Pematangsiantar adalah sebagai berikut :

Tabel 3. Dosen

\begin{tabular}{|l|l|}
\hline No & \multicolumn{1}{|c|}{ Nama Dosen } \\
\hline 1 & Agus Perdana Windarto, M.Kom \\
\hline 2 & Ahmad Fithrianto, S.Ag, M.A \\
\hline 3 & Alben Sigiro, S.Pd, M.Hum \\
\hline 4 & Amer Sharif, S.Si., M.Kom \\
\hline 5 & Anjar Wanto, M.Kom \\
\hline 6 & Asmarani, M.S.I \\
\hline 7 & Bahrudi Efendi Damanik, S.E, M.M \\
\hline 8 & Dameria Purba, S.T \\
\hline 9 & Dewi Kirana, S.E, M.M \\
\hline 10 & Dr. Dedy Hartama, S.T, M.KOM \\
\hline 11 & Drs. Nesar Achmad Khan, M.Pd \\
\hline 12 & Eka Irawan, M.Kom \\
\hline 13 & Eva Desiana, S.Kom., M.Kom \\
\hline 14 & Fitri Anggraini, M.Pd. \\
\hline 15 & Fitri Rizki, M.Pd \\
\hline 16 & Handrizal, S.Si., M.Comp.Sc \\
\hline 17 & Hasudungan Siahaan, S.Kom \\
\hline 18 & Hendry Qurniawan,S.Kom \\
\hline 19 & Heru Satria Tambunan, M.Kom \\
\hline 20 & Husnul Arifin S.Ag, S.Pd.I, M.Pd \\
\hline 21 & Ika Okta Kirana, M.Pd \\
\hline 22 & Ilham Syahputra Saragih, S.Sos, M.M \\
\hline 23 & Indra Gunawan, M.Kom \\
\hline 24 & Ir. Sufianto Mahfudz, M.Kom \\
\hline 25 & Irfan Sudahri Damanik, M.Kom \\
\hline 26 & Jalaluddin, S.Pd, M.Pd \\
\hline 27 & Jaya Tata Hardinata, M.Kom \\
\hline 28 & Khairil Anwar Uzir, S.H, S.Kom, M.Pd \\
\hline 29 & Letkol Inf Jon Heriko S.E, MM \\
\hline 30 & Lisnani, S.S., M.Pd \\
\hline 31 & M. Fauzan, M.E.I \\
\hline 32 & M. Safii, M.Kom \\
\hline 33 & Mawar Silalahi, S.Th, M.Pd.K \\
\hline 34 & Muhammad Zein, S.Pd.I, M.Pd.I \\
\hline 35 & Prof. DR. Muhammad Zarlis \\
\hline 36 & Rafiqa Dewi, M.Kom \\
\hline 37 & Sahmi Purba, M.PdK \\
\hline 38 & Saifullah, M.Kom \\
\hline 39 & Sumarno, M.Kom \\
\hline 40 & Victor Asido Elyakim Panggabean, M.Kom \\
\hline 41 & Zulaini Masruro Nasution,S.Pd.I., M. Pd \\
\hline
\end{tabular}


4. Waktu/Slot Matakuliah

Adapun data waktu perkuliahan di STIKOM Tunas Bangsa Pematangsiantar adalah sebagai berikut :

Tabel 4. Waktu / Slot Matakuliah
\begin{tabular}{|c|c|l|}
\hline No & Jam & Keterangan \\
\hline 1 & $08.00-09.40$ & Kuliah \\
\hline 2 & $09.40-09.59$ & Istirahat \\
\hline 3 & $10.00-11.40$ & Kuliah \\
\hline 4 & $11.40-13.59$ & Istirahat \\
\hline 5 & $14.00-15.40$ & Kuliah \\
\hline 6 & $15.40-16.09$ & Istirahat \\
\hline 7 & $16.10-17.50$ & Kuliah \\
\hline 8 & $17.50-17.59$ & Istirahat \\
\hline 9 & $18.00-19.30$ & Kuliah \\
\hline 10 & $19.30-20.50$ & Kuliah \\
\hline
\end{tabular}

\section{HASIL DAN PEMBAHASAN}

\subsection{Hasil}

Berisikan tampilan eksekusi atau implementasi dari sistem yang telah dibuat. Berikut adalah tampilan hasil dari implementasi perhitungan manual dari algoritma Integer Linear Programming.

a. Tampilan Data Screen

Pada halaman data screen silahkan masukkan tiap-tiap fungsi objektif dan fungsi kendala (constraint) pada kasus Integer Linear Programming, seperti Gambar 1. berikut ini :

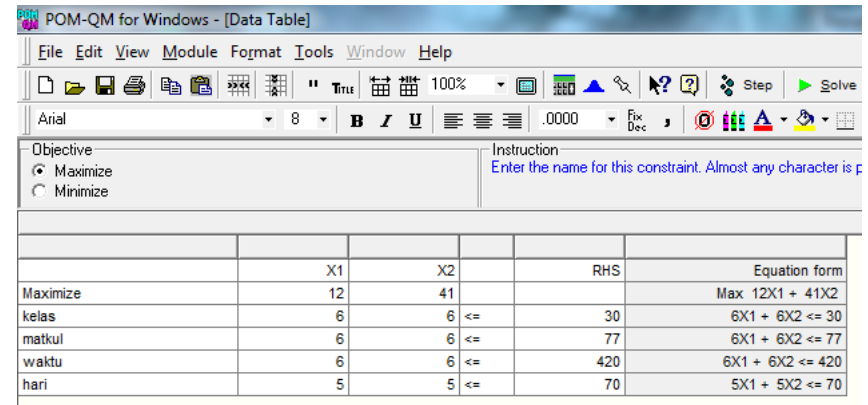

Gambar 1. Tampilan Datascreen

b. Tampilan Linear Programming Result

Pada halaman ini menampilkan hasil dari perhitungan optimal dari fungsifungsi yang dimasukkan pada dataset, hasil dari penelitian ini yaitu untuk nilai maximum $\mathrm{X}_{1}=0$ karena jumlah maximum dari $\mathrm{X}_{1}$ nilainya sama dengan jumlah persediaan ruangan maka nilai $\mathrm{X}_{1}$ menjadi 12 , dan nilai maximum $\mathrm{X}_{2}=$ 5 seperti Gambar 2. berikut ini : 


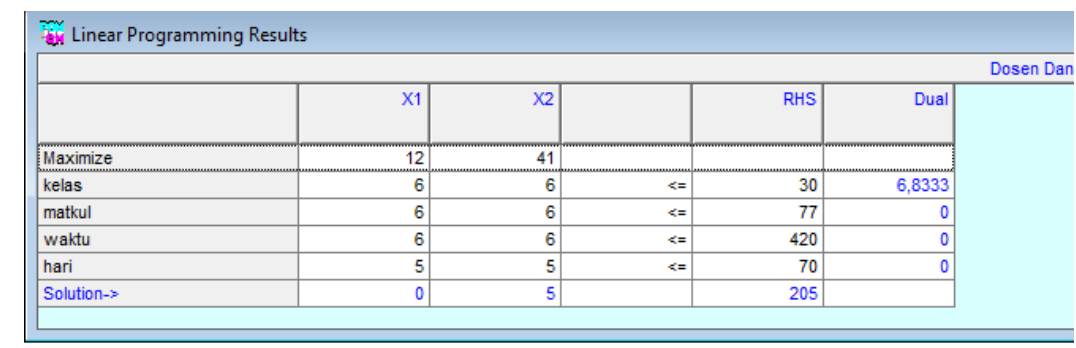

Gambar 2. Tampilan Linear Programming Result

c. Grafik

Grafik yang ditampilkan ini merupakan grafik yang menunjukkan hasil analisa persamaan lienar yang cari dengan bantuan software POM-QM for Windows. Penentuan titik kombinasi optimum dapat diketahui dengan melihat grafik yang didapat dengan pengoperasian software QM for Windows. Titik-titik potong grafik pada daerah berdasarkan persamaan dimasukkan ke dalam fungsi kendala. Dari 2 titik yang terbentuk, diperoleh kombinasi optimum dengan nilai X1 sebesar 0 dan X2 dengan nilai 5. Nilai ini menunjukkan bahwa jadwal optimal diperoleh saat nilai X1 dan X2 sebesar nilai tersebut. Pada grafik juga terdapat garis ungu putus-putus, yakni garis Isoprofit line, dimana menunjukkan bahwa sepanjang garis tersebut memiliki nilai maximum yang sama, tetapi dengan kombinasi output yang berbeda. Dapat dilihat pada Gambar 3. berikut :

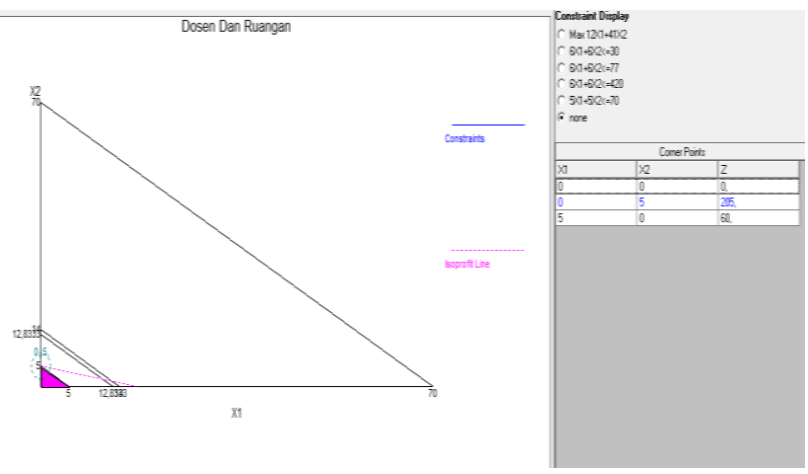

\subsection{Pembahasan}

Gambar 3. Grafik

Dari data yang telah peneliti jabarkan pada bab sebelumnya, maka dapat disimpulkan bahwa jumlah persediaan sumber daya, dan tujuan yang hendak dicapai adalah sebagai berikut:

Tabel 5. Sumber Daya

\begin{tabular}{|l|c|}
\hline \multicolumn{2}{|c|}{ Persediaan } \\
\hline Variabel & Jumlah \\
\hline Kelas & 30 \\
\hline Matakuliah & 77 \\
\hline Waktu & 6 \\
\hline Hari & 5 \\
\hline
\end{tabular}


Tabel 6. Tujuan

\begin{tabular}{|l|l|}
\hline \multicolumn{2}{|c|}{ Tujuan } \\
\hline Variabel & Jumlah \\
\hline Ruangan $\left(\mathrm{X}_{1}\right)$ & 12 \\
\hline Dosen $\left(\mathrm{X}_{2}\right)$ & 41 \\
\hline
\end{tabular}

Maka berdasarkan data tersebut dapat dinotasikan kedalam bentuk fungsi kendala (fungsi constraint) dan fungsi objektif (fungsi tujuan) sebagai berikut :

Fungsi Tujuan :

$\mathrm{Zmax}=12 \mathrm{X}_{1}+41 \mathrm{X}_{2}$

Fungsi Kendala (Constraint) :

$6 \mathrm{X}_{1}+6 \mathrm{X}_{2} \leq 30$

$6 \mathrm{X}_{1}+6 \mathrm{X}_{2} \leq 77$

$6 \mathrm{X}_{1}+6 \mathrm{X}_{2} \leq 420$

$5 \mathrm{X}_{1}+5 \mathrm{X}_{2} \leq 70$

Maka diperoleh hasil sebagai berikut :

Tabel 7. Simpleks

\begin{tabular}{|c|c|c|c|c|c|c|c|c|}
\hline $\begin{array}{l}\text { Variabel } \\
\text { Dasar }\end{array}$ & $\mathbf{Z}$ & $\mathbf{X}_{\mathbf{1}}$ & $\mathbf{X}_{\mathbf{2}}$ & $\mathbf{r}_{\mathbf{1}}$ & $\mathbf{r}_{\mathbf{2}}$ & $\mathbf{r}_{\mathbf{3}}$ & $\mathbf{r}_{\mathbf{4}}$ & $\mathbf{N K}$ \\
\hline $\mathbf{Z}$ & 1 & 29 & 0 & 6,806 & 0 & 0 & 0 & 205 \\
\hline $\mathbf{X}_{\mathbf{2}}$ & 0 & 1 & 1 & 0,166 & 0 & 0 & 0 & 5 \\
\hline $\mathbf{r}_{\mathbf{2}}$ & 0 & 0 & 0 & $-0,996$ & 1 & 0 & 0 & 47 \\
\hline $\mathbf{r}_{\mathbf{3}}$ & 0 & 0 & 0 & $-0,996$ & 0 & 1 & 0 & 390 \\
\hline $\mathbf{r}_{\mathbf{4}}$ & 0 & 0 & 0 & $-0,83$ & 0 & 0 & 1 & 45 \\
\hline
\end{tabular}

\section{KESIMPULAN}

Berdasarkan uraian yang telah diuraikan di atas, penulis dapat menyimpulkan bahwa, algortima Integer Linear Programming dapat diterapkan pada kasus Model Optimasi Penentuan Jumlah Dosen dan Ruangan Pada Proses Belajar Mengajar Dengan Model Integer Linear Programming, dengan menggunakan variabel Ruangan $\left(\mathrm{X}_{1}\right)$, Dosen $\left(\mathrm{X}_{2}\right)$, Kelas, Matakuliah, Waktu, Hari. Dengan fungsi tujuan $\mathrm{Zmax}=12 \mathrm{X}_{1}+41 \mathrm{X}_{2}$ dengan hasil hasil yang diperoleh bahwa jumlah maksimum ruangan yang dibutuhkan sama dengan jumlah persediaan ruangan yaitu 12, sedangkan jumlah maksimum dosen yang dibutuhkan untuk mengajar satu matakuliah yaitu 5 orang dosen. Kepada peneliti yang berikutnya ingin melanjutkan penelitian ini diharapkan nantinya dapat mengembangkan model perhitungan dari kasus ini menjadi lebih spesifik lagi, sebab penelitian ini hanya menggunakan 4 fungsi kendala yang hasilnya bersifat umum.

\section{DAFTAR PUSTAKA}

[1] D. E. Surya, "Kompetensi dosen terhadap standarisasi layanan kepada mahasiswa," Maj. IIm. UNIKOM, vol. 6, no. 2, pp. 157-168, 2006.

[2] M. Saidi-Mehrabad and P. Fattahi, "Flexible job shop scheduling with tabu search algorithms," Int. J. Adv. Manuf. Technol., vol. 32, no. 5-6, pp. 563-570, 2007.

[3] D. Abramson, M. K. Amoorthy, and H. Dang, "Simulated annealing cooling schedules for the school timetabling problem," Asia-Pacific J. Oper. Res., vol. 16, no. 1, p. 1, 1999.

[4] D. W. Nugraha, D. A. Y. Erwin, and S. A. T. S., "Sistem Penjadwalan Perkuliahan M Enggunakan Algoritm a Genetika ( Studi Kasus Pada Jurusan Teknologi Inform Asi Fakultas 
Teknik Universitas Tadulako )," Jimt, vol. 14, no. 2, pp. 242-255, 2017.

[5] C. Y. Livia and T. Oktiarso, "Penjadwalan Untuk Memininimalkan Total Tardiness Dengan Metode Integer Linear Programming,” vol. 18, no. 02, pp. 127-137, 2017.

[6] E. Desiana, "Performance Algoritma Genetika (GA) Pada Penjadwalan Mata Pelajaran," J. Nas. Inform. dan Teknol. Jar., vol. 1, no. 1, pp. 56-60, 2016.

[7] B. J. Maspaitella and J. M. Tupan, "( STUDI KASUS PADA JURUSAN TEKNIK INDUSTRI FAKULTAS TEKNIK UNIVERSITAS PATTIMURA AMBON," vol. 10, no. 1, 2016.

[8] T. M. Manik, "ANALISIS KARAKTERISTIK FUNGSI LAGRANGE DALAM MENYELESAIKAN PERMASALAHAN OPTIMASI BERKENDALA ABSTRAK," 2014.

[9] N. Gunantara, Teknik Optimasi, no. October. 2004.

[10] P. A. Everia, "PENJADWALAN KARYAWAN MENGGUNAKAN INTEGER LINEAR PROGRAMMING: STUDI KASUS DI TAMAN AIR TIRTAMAS PALEM INDAH JAKARTA," Fakultas Matematika dan Ilmu Pengetahuan Alam Institut Pertanian Bogor, 2016.

[11] A. S. P, S. Supian, and R. Sudrajat, "SIMULASI PENJADWALAN PEGAWAI MENGGUNAKAN TEKNIK INTEGER LINEAR PROGRAMMING," no. 13, pp. 1-10, 2015.

[12] I. M. Wirawan, "Pendekatan Komputasi Numerik Metode Regresi pada Penelitian yang Mengamati Suatu Kecendrungan/Trends Terhadap Peningkatan Hasil/Prestasi Belajar," Tekno, vol. 25 Maret 2, pp. 17-24, 2016.

[13] T. Riyanto, "Akuntabilitas Finansial dalam Pengelolaan Alokasi Dana Desa (ADD) di Kantor Desa Perangkat Selatan Kecamatan Marangkayu Kabupaten Kutai Kartenegara," eJournal Adm. Negera, vol. 3, no. 1, pp. 119-130, 2015.

[14] A. Paula and P. S. Kananlua, "Perbedaan Abnormal Return Dan Trading Volume Activity Saham Sebelum Dan Sesudah Reverse Split," Manag. Insight, vol. 7, pp. 1-11, 2012.

[15] M. R. Munandar, E. S. Astuti, and M. S. Hakam, "Pengaruh Keelamatan, Kesehatan Kerja (K3) dann Insentif terhadap Motivasi dan Kinerja Karyawan (Studi pada Pekerja Bagian Produksi PT. Sekawan Karyatama Mandiri Sidoarjo)," J. Adm. Bisnis, vol. 9, no. 1, pp. 1-9, 2014. 